\begin{tabular}{c} 
journal homepage: http://ijiemjournal.uns.ac.rs/ \\
International Journal of Industrial \\
Engineering and Management \\
volume $11 /$ No $2 /$ June $2020 / 93-103$ \\
\hline
\end{tabular}

Original research article

\title{
Performance Prediction through OEE-Model
}

\author{
CH. Anusha *, V. Umasankar \\ Vellore Institute of Technology, School of Mechanical Engineering, Chennai, Tamilnadu, India
}

\begin{abstract}
A B STRACT
Prediction of an organization's performance has become essential for any organization for its potential customers to place orders with confidence. Overall Equipment Effectiveness (OEE) is one of the acknowledged measures for performance monitoring. In this paper, two different techniques, a simple moving average and Holt's double exponential smoothing methods, are used to evaluate OEE and to predict the future performance of overall equipment effectiveness in $\mathbf{R}$ studio. Holts Double exponential smoothing method was found to result in minimum error measured by mean absolute deviation. Python program is to predict major losses to improve the productivity of the organization by management.
\end{abstract}

\section{ARTICLE INFO}

Article history:

Received October 3, 2019

Revised April 2, 2020

Accepted April 2, 2020

Published online April 29, 2020

Keywords:

Overall Equipment Effectiveness;

Simple moving average;

Holt's double exponential smoothing; Predictive analytics;

Losses

*Corresponding author:

Chintada Anusha

chintada.anusha@gmail.com

\section{Introduction}

Industry 4.0 is shifting all manufacturing industries on a platform of shared resources, That warrants for any potential customer to select the vendors on a reliable basis for which an established prediction system of future performance becomes imminent. Also, for successfully applied requirements of Industry 4.0, the production will be very flexible with high productivity and fewer resources [1]. In the present scenario of a competitive market, manufacturing industries are focusing on improving effective performance to sustain. In order to support the improvement of production processes, various techniques have been developed in Japan, throughout its industrialization quest. Total
Productive Maintenance [2] is a well-known method developed by Nakajima in 1971. It is a strategy that optimizes the effectiveness of equipment, eliminates breakdowns, and promotes autonomous maintenance by involving the total workforce in an organization. It also has a direct impact on improving overall production equipment performance [3]. It is a bottom-up approach where people from every department in an organization involve to enhance equipment efficiency and productivity.

Overall Equipment Effectiveness (OEE) is a measure of TPM that stipulates the effective functioning of equipment and machinery [4]. It tracks the actual performance of the machine concerning its performance capabilities under optimal manufacturing 
conditions [5]. It employs as a measure to compare companies effectiveness and efficiency irrespective of the type of industry. Usually, OEE is calculated manually by multiplying factors such as availability, performance, and quality. Benchmarking study is applied to select the best manufacturing practices to improve the performance of the production line and the total return of OEE [6]. The manufacturing companies analyses vital performance indicators by using appropriate software tools such as TAPS and AHP with the help of managers in making strategic decisions [7].In some studies, Excel is also used to evaluate OEE [8].

In this research, the future prediction of availability, performance, quality, and OEE aims from the past data using two different techniques(algorithms), namely Simple moving average and Holt's double exponential smoothing methods through $\mathrm{R}$ studio. It is an open-source language used in a wide range of data analysis fields and also developed for statistical analysis, data reconfiguration, and machine learning. $\mathrm{R}$ is flexible and extends with high speed [9]. It allows practicing a wide variety of statistical and graphical techniques like linear and nonlinear modeling, time-series analysis, classification, standard statistical tests, clustering, etc. Hence it is mostly used by data analysts, quantitative analysts, and research programmers for data importing and cleaning based on the user requirement.

Further, $\mathrm{R}$ is applied in many fields, such as finance, marketing, etc. Because of the advantages as mentioned above, $\mathrm{R}$ programming is a suitable selection to use data science approach. All these features make $\mathrm{R}$ the best choice for data science, big data analysis, and machine learning [10].

Every machine learning algorithm gives its best results based on the algorithm that fits its assumptions and the criteria for predicting the variables. In this work, we have developed two techniques for the prediction of OEE. Using each method, we have performed three accuracy models in R studio, such as mean absolute deviation, mean absolute percentage error, and root mean square error for evaluating the accuracy of OEE. These three accuracy models are compared in both the techniques and found that the mean absolute deviation method gives the minimum error.

The simple moving average is a technique that measures the overall trend of the data set. It measures the percentage of any subset from the data set. The simple moving average can be easily modified to fine-tune its performance and gets biased when the trend is consistent with minimum values [11]. The simple moving average is frequently accompanied by time-series data to smooth short term variation and emphasize long term trends or cycles. From the above statement, the result between the long term and short term depends on the approach. And the framework of a simple moving average is set accordingly. The simple moving average employs both long term investors and short term traders [12].

Holt's Double exponential smoothing method is adapted to track time series with a linear trend. This technique smooths the direction and slopes directly by using different smoothing constants [13]. This method responds more quickly to the most recent changes than the simple moving average. Hence we have identified that this method results in a minimum error when compared with the simple moving average method. Also, when we are using the model to predict the future trend with recent data, it is more effective in obtaining accurate values. In this paper, the smoothing constant $(\alpha)$ and trend constant $(\beta)$ have been given different values for smoothing the benefits. After many iterations, we found 0.1 for both $\alpha$ and $\beta$ to result in better smoothing.

The two different techniques are validated and compared based on error. From the analysis, we find that the Holts Double exponential smoothing method to result in a predicted value with a minimum error when compared with actual test data.

\section{Predictive Analytics}

Predictive analytics has gained importance in many industries as it enables well-informed decision making by identifying and eliminating real-time waste and predict the risk of downtime. In consideration of machine learning, Predictive analytics consists of two techniques, such as supervised learning and unsupervised learning. In this article, supervised learning is employed for two forecasting techniques by using historical data of OEE with the desired output. Also, a system algorithm is developed to consider any current trend by using Unsupervised learning. Unsupervised learning is applied in python, where the algorithm is developed based on the input information such as losses of availability, performance and quality, through which output is attained in the form of major losses that are affecting OEE.

This paper focuses on two different techniques of time series forecasting modeling. Time series forecasting works on time-based data and the unpredictable nature of the market, which we have been attempting to quantify. 
But for useful analytics, the right quality data, best practice application, and prediction of opportunities for improvement are essential [14]. It states that technology connected with development, implementation, and widespread use of computer systems based on mathematical modeling, through which performance of production can be improved [14]. Failure mode effect analysis identifies the root cause of the OEE measure to increase the productivity of an organization [15]. A controller and software augmented in visual basic calculates the OEE and collects the data automatically without the observation of the operator. This software analyses the data and predicts the losses and problem areas that are affecting overall equipment effectiveness [16]. It states that the simulation model demonstrates Predictions, recommendations, and dynamic optimization [17]. The Cloud computing-based simulation model manufacturing system is employed to improve efficiency and reduce costs related to production [18]. Prediction of OEE by applying statistical tools are employed to correlate assessment and predict the shutdowns for maintenance [19]. A Prediction tool is employed to capture real-time data from the production system and also used to forecast future data [20]. DMAIC, statistical process control, and Autonomous maintenance are applied to evaluate the OEE measure through autonomous maintenance that helps to identify the loss mechanism of the equipment where it even cannot be noticed by production personnel that results in enhanced OEE [21]. Minitab 16 is applied to identify the influencing factor and classic relation between availability, performance, and quality rate by employing regression analysis [22].

The predictive model related to forecasting techniques is developed for determining the accuracy of OEE, predicting future events in overall equipment effectiveness through $\mathrm{R}$ studio, as shown in Figure 1.

Prediction accuracy is essential to achieve the desired results. Hence the recent one-year data is always taken for prediction.

\section{Methodology}

\subsection{Data quality}

The Overall Equipment effectiveness data for one year is collected from the Auto ancillary company. We have noticed that there is an inconsistency within OEE data where parameters affecting OEE are having more influence than achievable, which results in the variation of equipment efficiency. To achieve the accuracy in predicted OEE data, the normalization of availability, performance, quality, and OEE data is carried out in the Anderson darling test by using Minitab, as shown in Table 1.

The obtained p values are as shown in Table 2 and Figure 2.

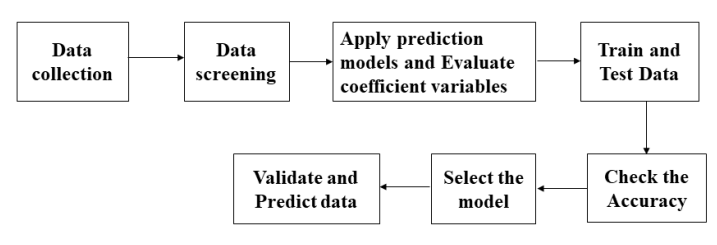

Figure 1. Predictive Analytics

Table 1. Normalized data of three parameters and OEE

\begin{tabular}{ccccccccccc}
\hline SNO & 1 & 2 & 3 & 4 & 5 & 6 & 7 & 8 & 9 & 10 \\
\hline Availability & 73 & 68 & 56 & 42 & 50 & 49 & 40 & 58 & 69 & 63 \\
Performance & 88 & 82 & 91 & 75 & 76 & 62 & 58 & 50 & 83 & 87 \\
Quality & 76 & 80 & 78 & 82 & 72 & 70 & 74 & 80 & 80 & 82 \\
OEE & 64 & 62 & 52 & 53 & 51 & 49 & 54 & 57 & 57 & 56 \\
\hline
\end{tabular}


Anderson darling test is a normality test that is developed to detect departures from normality. The test rejects the hypothesis of normality when the p-value is less than or equal to 0.05. The test accepts the premise of normality when there are no significant departures. The data is employed in the forecasting model to predict the occurrence of future events through which the data quality is improved and also to attain higher accuracy in data.

\section{Model Selection for predicting OEE}

A random effect non-linear regression model specifies the constant time model, which was applied to formulate a prediction model for the learning rate. A two-stage analysis was implemented to evaluate the parameters and monitor OEE [23]. The three metrics and OEE data for one year is considered for selection, prediction, and validation using an algorithm. $\mathrm{R}$ studio develops the simple moving average

Table 2. P value of three parameters and OEE and Holt's Double exponential smoothing model for the prediction of data. The availability, performance, quality, and OEE data imports into the $\mathrm{R}$ studio file. In $\mathrm{R}$ studio, we found training, testing, and prediction of data by using two algorithms. One is a simple moving average, and the second is Holt's double exponential smoothing, as shown in Figure 3.

The evaluation of the accuracy of output data determined by mean absolute deviation, mean absolute percentage error, and root mean square error. The mean absolute deviation of a data set defines the sum of the difference between the predicted value and the average divided by the amount of the number of data points. Mean absolute percentage error is the measure of prediction accuracy of a forecasting method in statistics. Mean absolute deviation can be easily understandable by non-specialists. It is less sensitive to the effects of outliers and gives a better estimate of average error when the distribution of error is far from normal [23]. Mean absolute deviation is employed for forecasting to minimize the error

\begin{tabular}{ccccc}
\hline SNO & 1 & 2 & 3 & 4 \\
\hline Parameters & Availability & Performance & Quality & OEE \\
P-Value & 0.337 & 0.493 & 0.249 & 0.332 \\
\hline
\end{tabular}
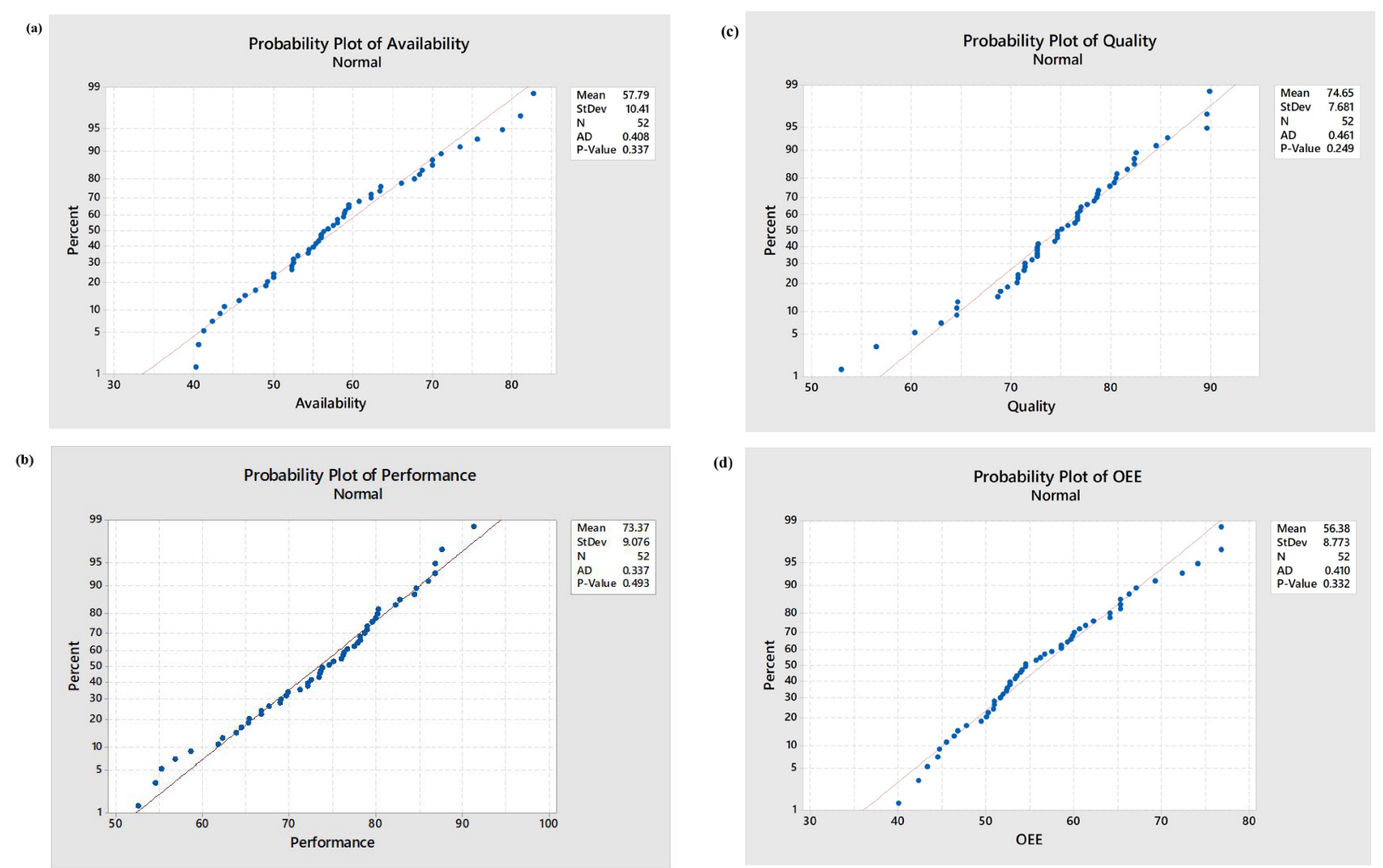

Figure 2. Anderson Normalization test for (a)Availability (b) Performance (c) Quality (d) OEE 
function [24]. Root mean square error measures the difference between values predicted by the model and the values observed from the environment that is being modeled. From the above three accuracy methods, the mean absolute deviation is selected in this work due to intermittent and low volume data. It is also observed that the percentage of errors cannot be calculated when actuals are zero, and it takes extreme values when dealing with low volume data in case of mean absolute percentage error, which has overcome by mean absolute deviation as it is divided by the mean. In the case of Root mean square error, it gives more significant error compared to mean absolute deviation, and also, as the test sample increases, the Root mean square value increases. Thus, the mean absolute deviation executes minimum error as compared to the other two methods. The mean absolute deviation is taken within the two models to calculate the accuracy of data in which mean absolute deviation has shown minimum error in Holt's Double exponential smoothing method as compared to the simple moving average.

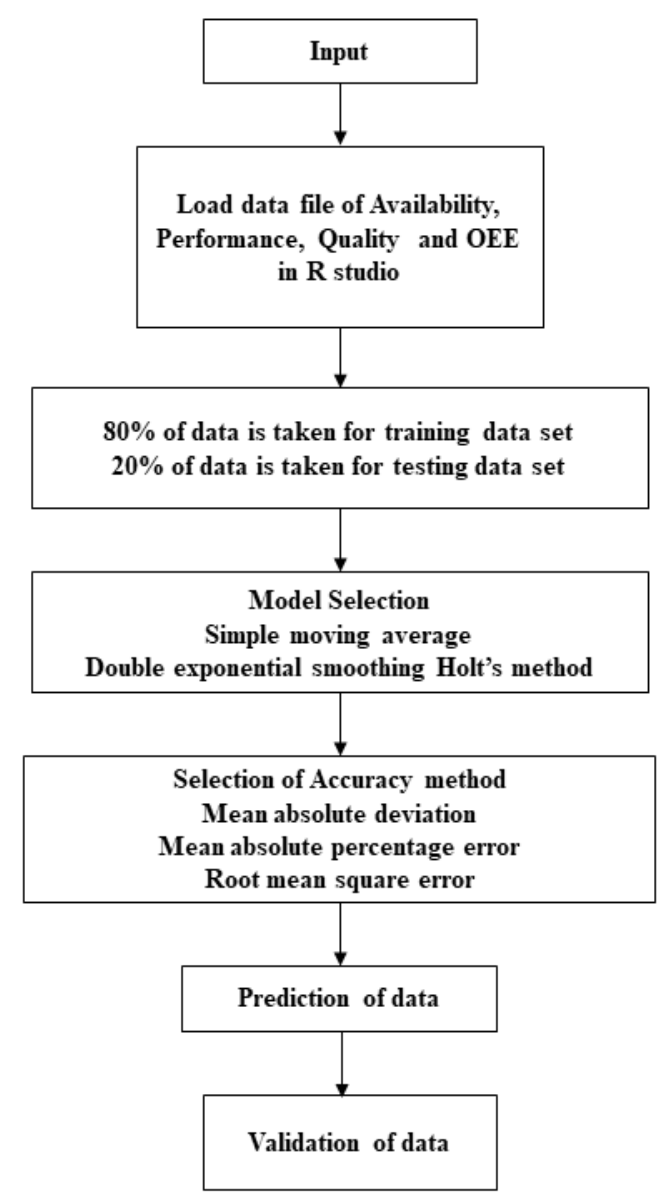

Figure 3. Flow chart on forecasting model to predict the data through R studio

\section{Loss accounting}

OEE is a performance measurement tool that accounts for different types of production losses and used for identifying areas of process improvement [25]. Overall equipment effectiveness aims to determine six major losses, such as breakdown, set up and adjustment, idling and minor stoppage, speed, yield, and Quality defects and rework losses. Overall equipment effectiveness is taken as a benchmark to compare the performances of the machinery in the plant [26]. The OEE and six losses can be identified effectively by cross-functional teams in an organization [27].

Overall Equipment Effectiveness of one-year data from an Auto ancillary industry that has successfully challenged the TPM award for excellence was collected. The data consists of planned production time in minutes per shift, total losses, Net operating time, Ideal rate parts/hour, Parts/Minute, total parts produced, total parts rejected, total good parts through which availability, performance, and quality are obtained. From the data, it is observed that only a few losses are taken into consideration for calculating OEE, which affects the efficiency of the machine. And also, human error is found when the OEE data is calculated manually. To avoid human error in the calculation of $\mathrm{OEE}$ and to predict the major losses that are affecting OEE, in the present work, the OEE data is used to develop a predictive model, which is expected to provide overall productivity as well as major losses. The major factors affecting OEE are predicted by the python program through which manufacturing personnel can rectify the problems in the machine and improve the effectiveness of the equipment. Python is extensively applied for scientific computing in both academia and industry through which a large number of analytical packages are available such as numerical computing, data analysis, statistical analysis, visualization, and machine learning [9]. The model enables the management for easy monitoring and controlling the losses; thereby, overall equipment effectiveness can be improved.

The framework for predicting overall equipment effectiveness is made on fifteen losses of OEE, as shown in Figure 4.

Later on, the output is represented in the form of a graph that enables the major factors affecting availability, performance, and quality. The program logic involved in attaining the significant factors affecting OEE is shown in Figure 5.

The program is developed in python, in which the losses of availability, performance, and quality are 


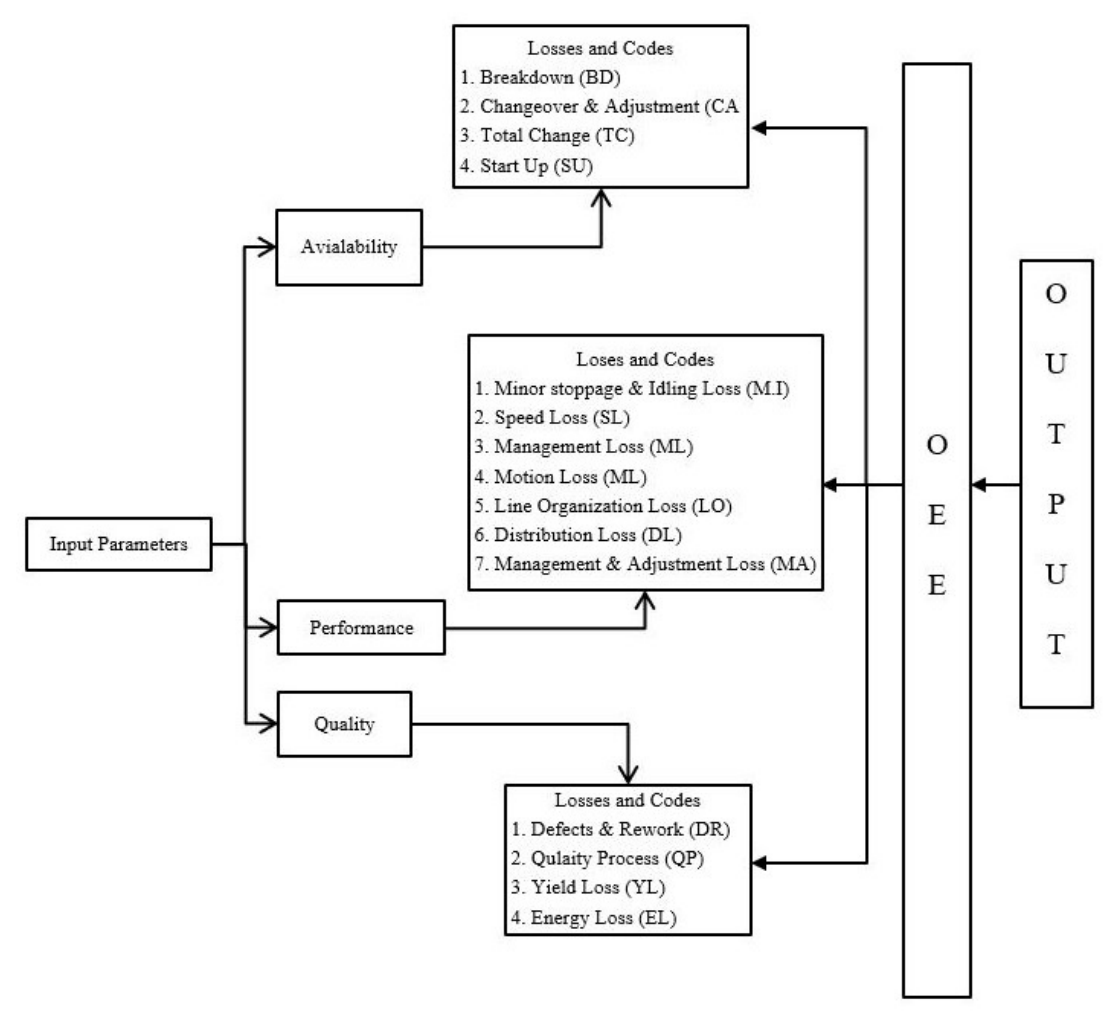

Figure 4. A frame work for Major factors effecting Overall equipment effectiveness

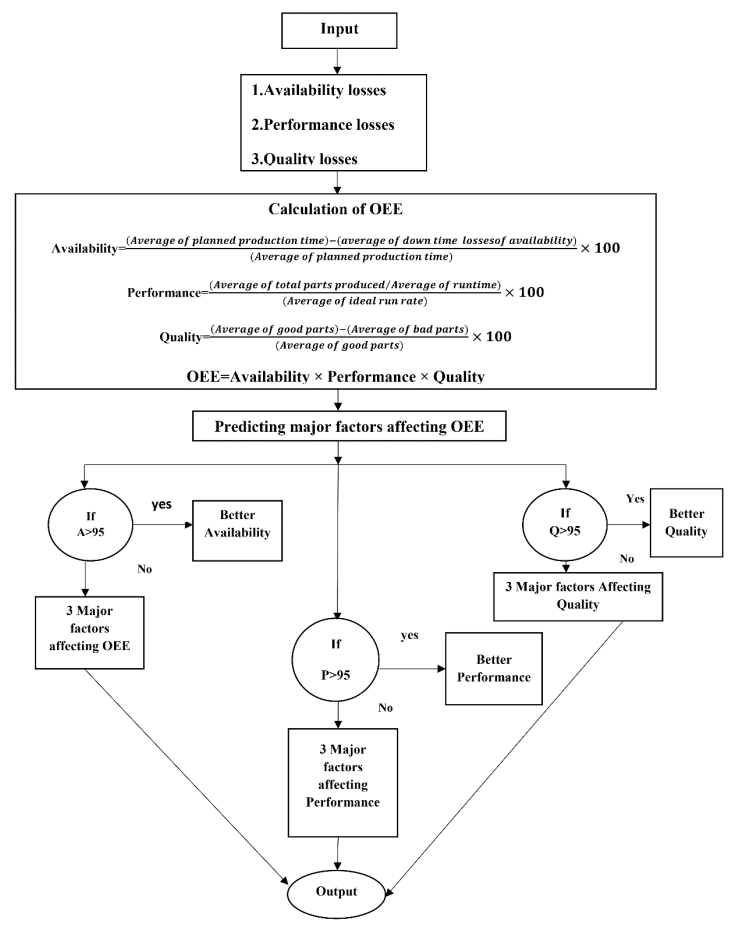

Figure 5. Flow chart on prediction of Major factors affecting OEE

considered as input, and OEE is determined as output. This program is able to establish the major factors that are affecting overall equipment effectiveness through equipment losses. The collected OEE data of one year is segregated into fifteen losses based on the type of problems that occurred in the machine. By the identification of major factors affecting OEE, production personnel will be able to prevent the malfunctioning of a machine.

\section{Results and discussion}

\subsection{Prediction of data}

The data of one year is taken for two forecasting techniques in $\mathrm{R}$ studio, in which $80 \%$ of data is taken for training, and $20 \%$ of data is taken for testing, prediction, and validation of data. The prediction of parameters and OEE are shown in Figure 6(a) to Fig- 
ure 6 (d).

It is observed that in Holt's double exponential smoothing method, the process constant alpha and trend constant beta has given optimal values from the range of 0 to 1 . It is observed that the larger the values of alpha and beta reduce the level of smoothing and provides a maximum error. Hence, when the alpha and beta values are given as 0.8 , the error value increases, and when the smoothing constants are given 0.4 and 0.1 , the error gradually decreases. It is observed that a value of 0.1 both alpha and beta the mean absolute deviation is offering a minimum error in Holt's double exponential smoothing constant.

For the above analysis, the data of availability, performance, quality, and OEE for 3months, 6months, and 12 months have been considered and compared within alpha-beta values at $0.8,0.4$, and 0.1 , as shown in Figure 7 (a) to Figure 7 (d).

The error percentage of data is compared within the two techniques for 3months, 6months, and 12 months each for all the parameters with the optimal value of 0.1 for alpha and beta in Holt's double exponential smoothing is compared with the simple moving average method. It is observed that simple moving average attains minimum error at short term period of 3 months gradually error increases for the long term period of 12 months whereas the error value will be decreasing in the Holts double exponential smoothing method as long as the time increases in which the level of smoothing reduces and forecast value is nearer to actual value as shown in figure 6 . As the large data is taken for prediction, one-year data is considered for prediction of OEE with minimum error, and the mean absolute deviation is compared within two methods. And the accuracy of data is measured by mean absolute deviation, which proves Holt's double exponential smoothing gives minimum error percentage compared to the simple moving average, as shown in Figure 8 (a) to Figure 8 (d).

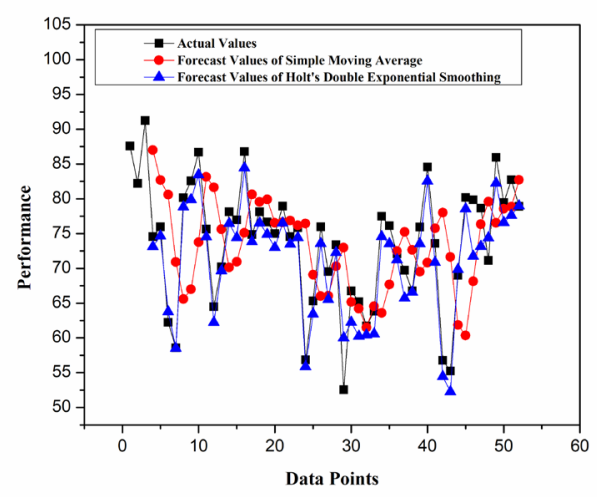

Figure 6 (b). Graphical representation of Prediction of Performance

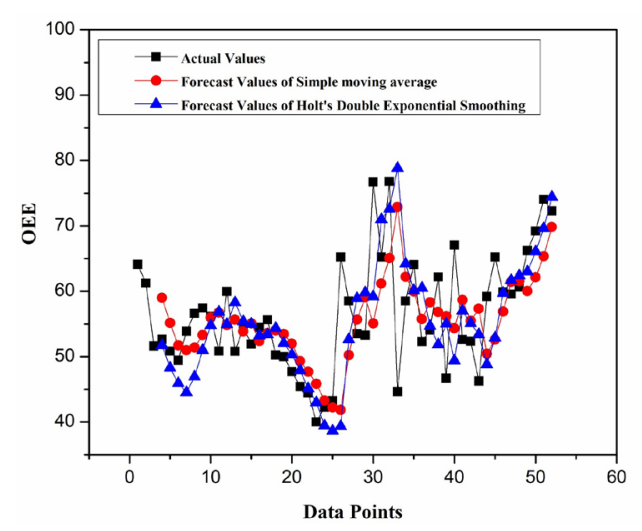

Figure 6 (d). Graphical representation of Prediction of OEE
Figure 6 (c). Graphical representation of Prediction of Quality

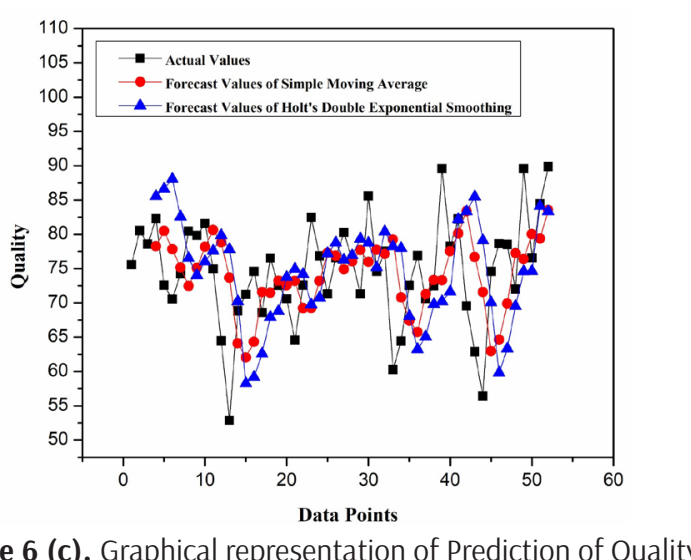




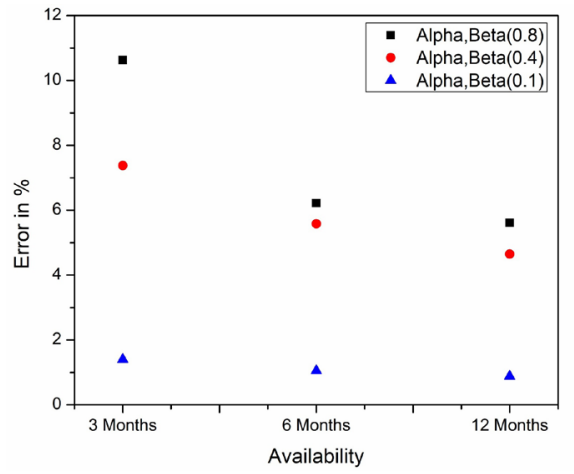

Figure 7 (a). Graphical representation of error percentage of availability at alpha, beta value $(0.8,0.4,0.1)$ for 3 months, 6 months and 12 months

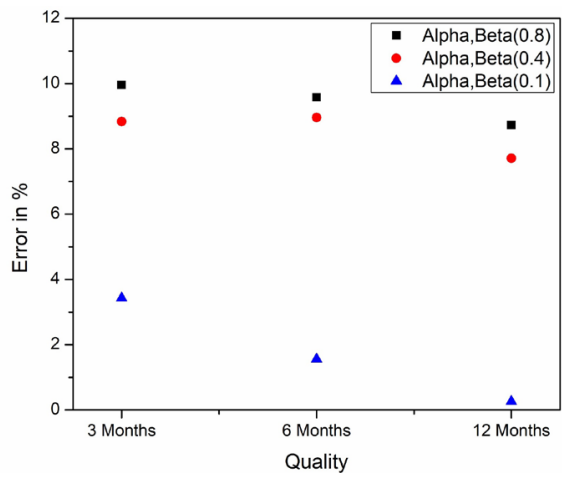

Figure 7 (c). Graphical representation of error percentage of Quality at alpha, beta value $(0.8,0.4,0.1)$ for 3 months, 6 months and 12 months

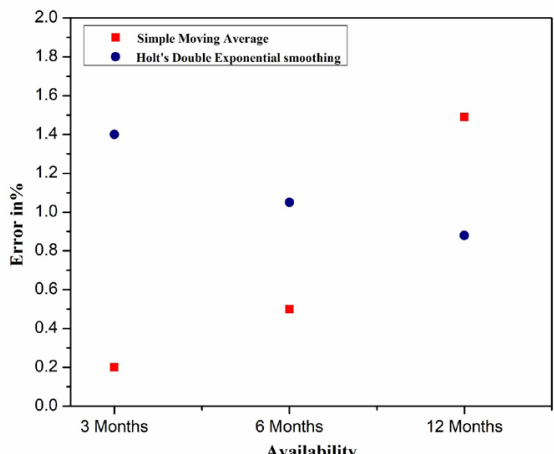

Figure 8 (a). Comparison of error percentage of Availability at alpha, beta value (0.1) for 3months, 6 months and 12 months within simple moving average and Holts Double Exponential smoothing Method

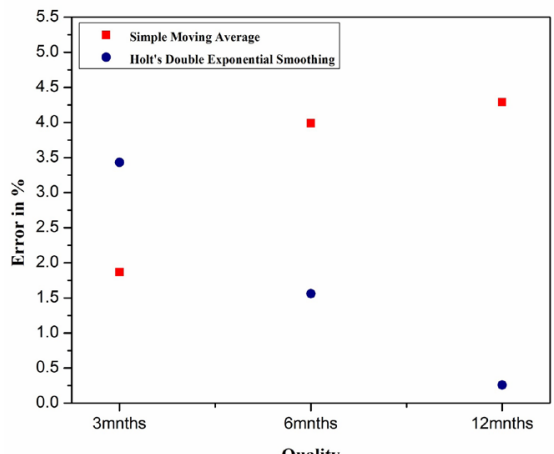

Figure 8 (c). Comparison of error percentage of Quality at alpha, beta value (0.1) for 3 months, 6 months and 12 months within simple moving average and Holts Double Exponential smoothing

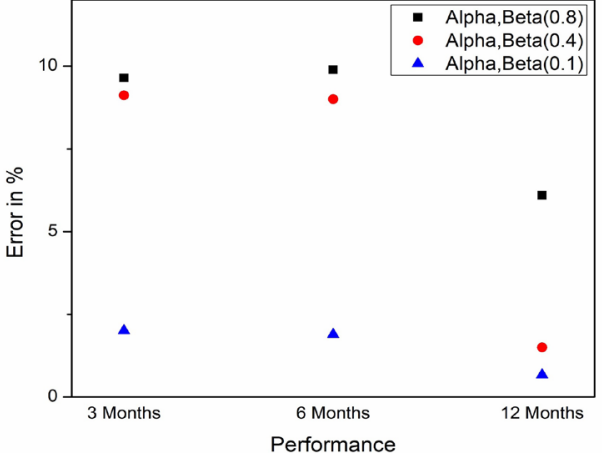

Figure 7 (b). Graphical representation of error percentage of Performance at alpha, beta value $(0.8,0.4,0.1)$ for 3 months, 6months and 12 months

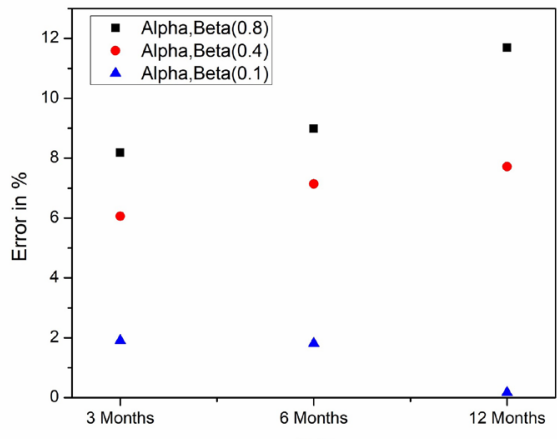

OEE

Figure 7 (d). Graphical representation of error percentage of OEE at alpha, beta value $(0.8,0.4,0.1)$ for 3 months, 6months and 12 months

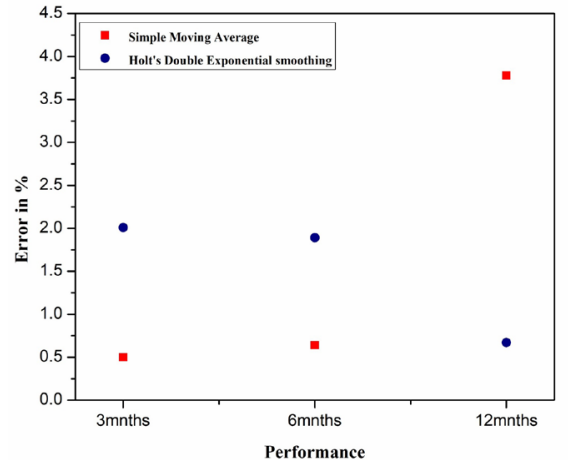

Figure 8 (b). Comparison of error percentage of Performance at alpha, beta value (0.1) for 3 months, 6 months and 12 months within simple moving average and Holts Double Exponential smoothing Method

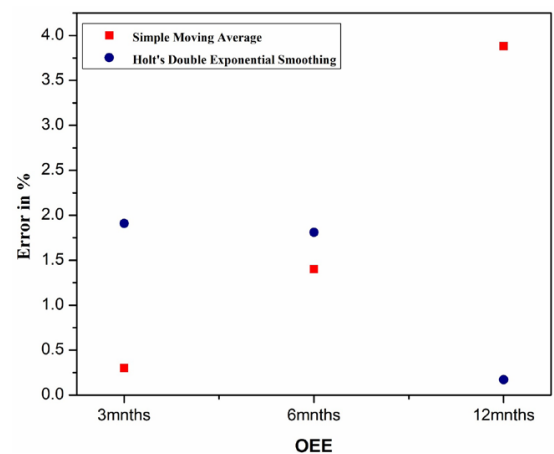

Figure 8 (d). Comparison of error percentage of OEE at alpha, beta value (0.1) for 3months, 6 months and 12 months within simple moving average and Holts Double Exponential smoothing Method 
The algorithm was validated with test data and found to be in good agreement within a $0.2 \%$ error. Thus, from the prediction of data, major losses that are affecting OEE can be identified in turn increases productivity.

\subsection{Major Factors affecting Overall Equipment effectiveness}

Overall equipment effectiveness is affected by the major factors of availability, performance as shown in Figure 9.

From Figure 9, it is observed that the breakdown loss, management loss, and distribution loss are the major losses affecting the efficiency of the machine. From the obtained losses, we have noticed that the availability of the machine is $89 \%$, the performance of the machine is $62 \%$, and quality is $99.74 \%$ by which the OEE is obtained as 55\%, as shown in Figure 10.

It is also observed that the overall equipment effectiveness of the machine is less when compared to the standard OEE i.e $80 \%$ due to the performance of the machine which is affected by management loss. In order to avoid the losses that occurred in the ar- eas of the machine, personal from engineering and production have to be involved in rectifying the problems in the machine. Also, by predicting the losses that are occurred before the breakdown of the machine the OEE of the machine is improved and the productivity of the organization is increased.

\section{Conclusion}

Overall equipment effectiveness evaluation and the prediction algorithm for a future period of one year was developed and validated. It was found that a simple moving average is incapable of recording sudden changes in data and fails to reflect the forecast nearer to actual. Out of simple moving and Holt double exponential smoothing methods, the Holt's double exponential smoothing method was found to have minimum error $(0.17 \%)$. The self-learning program was developed to predict the OEE using python. The data obtained from python help Manufacturing Information System (MIS) to determine the major factors affecting OEE. This enables the assessment and prediction of OEE in a dynamic system

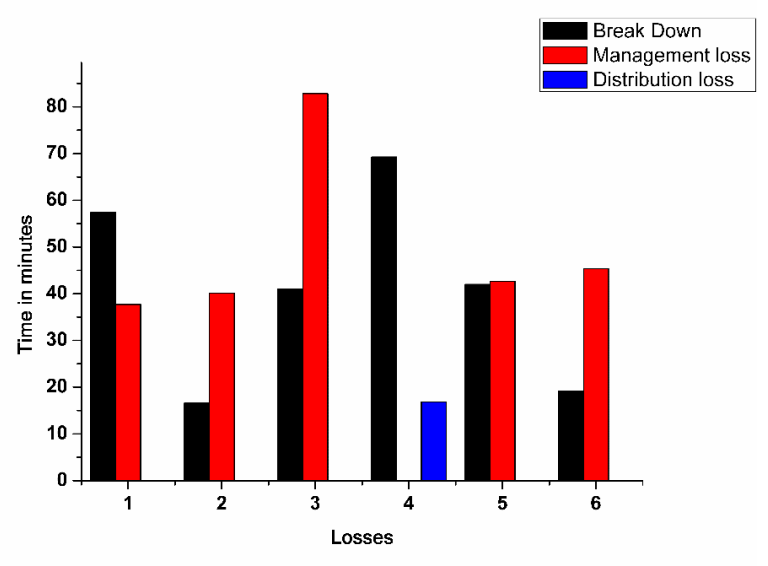

Figure 9. Major factors that are affecting Overall equipment efficiency

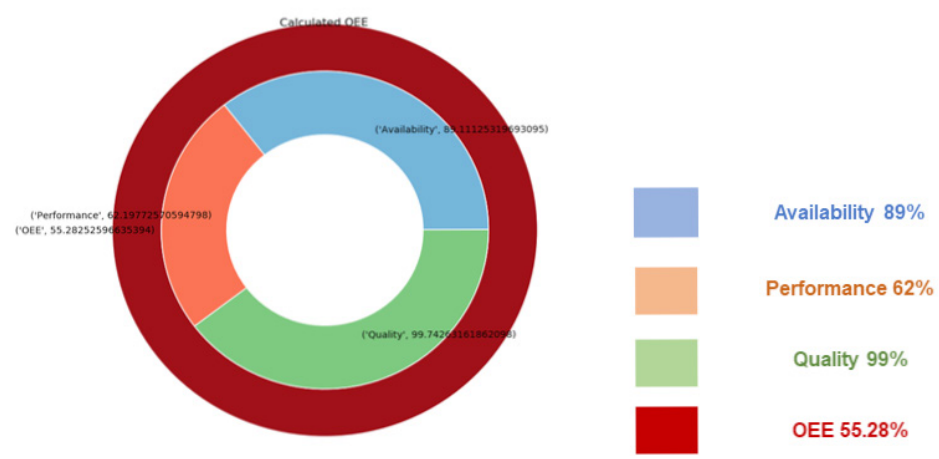

Figure 10. Overall Equipment Effectiveness 
with better accuracy and can be integrated into a system for automatic capturing and prediction of useful MIS information. The system enables the prediction of major losses from the existing data, which will be very useful to make intelligent decisions for the customer orders at any point in time. Thus the current research plays an essential purpose in progressing Industry 4.0.

\section{Funding}

This research did not receive any specific grant from funding agencies in the public, commercial, or not-for-profit sectors.

\section{References}

[1] M.Crnjac, I. Veža, N. Banduka, "From concept to the introduction of Industry 4.0," International Journal of Industrial Engineering and Management., vol. 8, no.1, pp.21-30,March. 2017, UDK: 005.1 658.5.

[2] Becker, Juan M. Jauregui, Jesper Borst, and Abele van der Veen, "Improving the overall equipment effectiveness in high-mix-low-volume manufacturing environments," CIRP Annals-Manufacturing Technology., vol. 64, no.1, pp.419422,May. 2015, doi:10.1016/j.cirp.2015.04.126

[3] Hooi, Lai Wan, and Tat Yuen Leong. "Total productive maintenance and manufacturing performance improvement," Journal of Quality in Maintenance Engineering, vol. 23, no. 1 pp. 2-21, March. 2017, doi:10.1108/JQME-07-2015-0033.

[4] LBSPartners. "TPM and OEE". [Online]. Available: https://www.lbspartners.ie/wp-content/uploads/2018/12/ TPM-OEEEBook_LBSPartners.pdf.[Accessed:December $-2015]$.

[5] Anvari, Farhad, Rodger Edwards, and Andrew Starr. "Evaluation of overall equipment effectiveness based on market," Journal of Quality in Maintenance Engineering, vol. 16, no. 3, pp. 256-270, 2010, doi:10.1108/13552511011072907.

[6] Fattah, Jamal, Latifa Ezzine, and Abdeslam Lachhab. "Evaluating the Performance of a Production Line by the Overall Equipment Effectiveness: An Approach Based on Best Maintenance Practices," In International Journal of Engineering Research in Africa, vol. 30, pp. 181-189, Trans Tech Publications Ltd, May.2017, doi:10.4028/www.scientific.net/JERA.30.181.

[7] Tomić, Miloš, Zdravko Tešić, Bogdan Kuzmanović, and Ivana Tomić, "A Model for Analyzing and Measuring the Performance of Industrial Enterprises," International Journal of Industrial Engineering and Management., vol.6, no.1, pp. 21-28, March 2015, UDK: 007:004.

[8] Relkar, S.Anand, and K. N. Nandurkar, "Optimizing \& analysing overall equipment effectiveness (OEE) through design of experiments (DOE)," Procedia Engineering., vol. 38, pp. 2973-2980, 5 september 2012, doi:10.1016/j.proeng.2012.06.347.

[9] Christian B. Madsen, Estelle Cormier, Javier Von Stecher, Kuo Liu, Gennady Voronov, Hans Gu, Ed Wiley. "Python for Analytics and The Role of R." [Online]. Available at: https://www.seagate.com/files/www-content/ti-dm/_shared/ images/r-and-python-pv0026-1-1409us.pdf [Accessed September 2014]
[10] Newgenapps. "Why choose R programming for data science projects?.” [Online]. Available:https://www.newgenapps. $\mathrm{com} / \mathrm{blog} / 6$-reasons-why-choose-r-programming-for-datascience-projects.[Accessed: 18-Sep-2017].

[11] Robert Nau, "Forecasting with moving averages." [Online]. Available at: http://people.duke.edu/ ${ }^{\sim} \mathrm{rnau} /$ forecasting.htm. [Accessed August 2014].

[12] Cory Mitchell. "How to Use a Moving Average to Buy Stocks.” [Online]. Available at:https://www.investopedia. com/articles/active-trading/052014/how-use-movingaverage-buy-stocks.asp[Accessed 6 May 2019].

[13] S.Hansun, "H-WEMA: A New Approach of Double Exponential Smoothing Method," Telkomnika., vol. 14, no. 2, pp. 772-777, Jun. 2016, doi: 10.12928/telkomnika.v14i2.3096.

[14] V. V. Lavrov, and N. A. Spirin, "Automated information system for analysis and prediction of production situations in blast furnace plant." In IOP Conference Series: Materials Science and Engineering 150, 2016pp. 012010, doi: 10.1088/1757-899X/150/1/012010.

[15] C.P. Ahire and A.S. Relkar, "Correlating failure mode effect analysis (FMEA) \& overall equipment effectiveness (OEE)," Procedia Engineering., Vol.38, pp.3482-3486, Jan.2012,doi:10.1016/j.proeng.2012.06.402.

[16] R. Singh, D.B. Shah, A.M. Gohil, and M.H. Shah, "Overall Equipment Effectiveness (OEE) calculation-Automation through hardware \& software development, "ProcediaEngineering., vol. 51, pp. 579-584, April 2013, doi:10.1016/j.proeng.2013.01.082.

[17] M. Pospíšil, V. Mates, T. Hruška, and V. Bartík, "Process mining in a manufacturing company for predictions and planning." International Journal on Advances in Software. , vol. 6, no. 3 \& 4, 2013, doi: 10.1.1.672.4578\&rep=rep $1 \&$ type $=$ pdf.

[18] C.L. Huang and C.C. Huang, "Cloud computing-based intelligent manufacturing scheduling system using the quality prediction method," Transactions of the Canadian Society for Mechanical Engineering., vol.37, no. 3, pp.981-989,2013, doi:10.1139/tcsme-2013-0084.

[19] R.J.K. Netto, E.A.P. Santos, E.D.F.R. Loures, and R. Pierezan, "Using Overall Equipment Effectiveness (OEE) to predict shutdown maintenance," In Engineering systems and networks., Springer, pp. 13-21, Dec. 2016 doi: 10.1007/978-3-319-45748-2_2.

[20] P.A. Hillberg, S. Sengupta, and R.P. Van Til, "A Comparative Study of the Three Predictive Tools for Fore casting a Transfer Line's Throughput," International Journal of Industrial Engineering: Theory, Applications, and Practice., vol.16, no.1, pp.32-40,2009.

[21] A. Azizi, "Evaluation Improvement of Production Productivity Performance using statistical process Control, Overall Equipment Efficiency, and Autonomous Maintenance," Procedia Manufacturing., vol. 2, pp. 186-190, October 2015, doi:10.1016/j.promfg.2015.07.032.

[22] M. Lalkiya, and D.K. Kushwaha, "Optimizing \&Analyzing Overall Equipment Effectiveness Through TPM Approach: A Case Study In Cement Industry," vol.2, no.5, pp.807-811, May 2015.

[23] F.K. Wang and W. Lee, "Learning Curve Analysis in Total Productive Maintenance." The International Journal of Management Science., vol.29, no.6, pp.491-499, Dec.2001, doi:10.1016/S0305-0483(01)00039-1.

[24] H.V. Ravinder, "Forecasting With Exponential Smoothing What's The Right Smoothing Constant?," Review of Business Information Systems (RBIS), vol.17,no.3, pp.117-126,Aug.2013,doi:10.19030/rbis.v17i3.8001.

[25] P. Muchiri and L. Pintelon, "Performance measurement using overall equipment effectiveness (OEE): literature re view and practical application discussion.” International 
Journal of Production Research., vol.46, no.13, pp.35173535,Apr.2008, doi:10.1080/00207540601142645.

[26] B. Dal, P.Tugwell and R. Greatbanks, "Overall equipment effectiveness as a measure of operational improvement-a practical analysis," International Journal of Operations \& Production Management., vol.20, no.12, pp.1488-1502, Dec. 2000, doi:10.1108/01443570010355750.

[27] C.J. Bamber, P.Castka, J. M. Sharp, Y. Motara, "Crossfunctional team working for Overall Equipment Effectiveness(OEE)", Journal of Quality in Maintenance Engineering., Vol. 9 No. 3, pp. 223-238, Sep. 2003, doi:10.1108/13552510310493684 